\title{
Dimensión sociopolítica del maestro: un estudio de su relación con las concepciones, formación profesional y experiencias en un colectivo de maestras
}

\author{
Sociopolitical dimension of the teacher: a study of their relationship with the conceptions, \\ professional training and experiences of a group of teachers
}

\section{Resumen}

La investigación "Conceptos, enfoques y experiencias pedagógicas de la Mesa por la Calidad de la Educación de Floridablanca” sobre la formación sociopolítica del maestro se realizó en el 2000 en la Universidad Industrial de Santander. Algunas maestras del sector oficial del departamento de Santander presentan diferentes formas de organización: emergentes, autogestionarias, autónomas, así como las maestras que hacen parte de las Mesas por la Calidad de la Educación. Éstas muestran concepciones fruto de su formación y en el desempeño de su profesión desarrollan experiencias en las que puede evidenciarse la dimensión sociopolítica. Esta investigación tuvo como objetivo analizar

los componentes de las concepciones pedagógicas, los enfoques en la formación y las experiencias que han contribuido al desarrollo de la dimensión sociopolítica de las maestras que integran la Mesa por la Calidad de la Educación de Floridablanca (MCEF).

Palabras clave Acción transformadora, concepciones, dimensión sociopolítica, formación, pedagogía radical.

\section{Abstract}

The research "Concepts, approaches and educacional experiences of the table for quality of education in Floridablanca", the sociopolitical dimension of the teacher was done in 2002 at the Universidad Industrial de Santander. Some teachers from the official sector

of the department of Santander have different ways of organizing self-managed, selfemerging, as the teachers are part of the tables for the quality of education which shows conceptions, result of their training and in their professional performance develop experiences in which socio-political dimension is evidenced. This study aimed to: analyze the components of educational ideas, approaches in the training and experiences that have contributed to the development of socio-political dimension of the teachers that make up the table for the quality of education of Floridablanca (MCEF).

Keywords Transforming action, conceptions, sociopolitical dimension, formation, radical pedagogy.
Alicia Téllez-Fajardo*

Recibido: 4 de marzo del 2011 Aprobado: 18 de abril del 2011
Cómo citar este artículo: Téllez-Fajardo, Alicia (2011), “Dimensión sociopolítica del maestro: un estudio de su relación con las concepciones, formación profesional y experiencias en un colectivo de maestras", en Rastros Rostros, vol. 13, núm. 25, pp. 39-50.

* Licenciada en Educación Básica con énfasis en Organización Comunitaria de la Universidad Santo Tomás. Magíster en Pedagogía de la Universidad Industrial de Santander. Coordinadora del programa de Licenciatura en Educación Básica con énfasis en Humanidades, Lengua Castellana e Inglés de la Universidad Cooperativa de Colombia, sede Bucaramanga. Correo electrónico: alicia.tellez@ucc.edu.co 


\section{Introducción}

E sta investigación identificó algunos elementos de análisis para resignificar la función social de la profesión de maestro, tanto en la formación inicial, como en su desempeño, para lo cual se hizo un estudio de las concepciones, la formación y las experiencias que han enmarcado el ejercicio profesional de diez maestras que forman un colectivo denominado Mesa por la Calidad de la Educación de Floridablanca. Para enriquecer esta construcción también se entrevistó a seis maestros investigadores de diferentes nacionalidades, ${ }^{1}$ quienes aportaron nuevos elementos para la conceptualización acerca de la dimensión sociopolítica del maestro.

La dimensión sociopolítica en este estudio se asume como el desarrollo de capacidades, actitudes $\mathrm{y}$ valores que han posibilitado a las maestras del colectivo y a los investigadores ser actores sociales de cambio en las comunidades educativas donde éstas ejercen su labor como formadoras de nuevos ciudadanos, en otras palabras, ser maestras con una visión política y unas capacidades para comprender las problemáticas sociales y actuar sobre ellas, en y con las comunidades a través de una práctica pedagógica transformadora.

La concepción, según Giordán y de Vechi (de Venchi, 1995), es un proceso personal, por el cual el individuo estructura su saber a medida que integra los conocimientos. Este saber se elabora, en la mayoría de los casos, durante un periodo bastante amplio de la vida, a partir de su arqueología, es decir, de la acción cultural parental, de la práctica social del niño en la escuela, de la influencia de los diversos medios de comunicación, y más tarde de la actividad profesional y social del adulto. La concepción

Para la investigación se entrevistó a Alberto Vilar, secretario del Foro mundial por la educación, a Orlando Fals Borda investigador social colombiano (q.e.p.d.), Miguel Dualde, sindicalista argentino, a Roberto Pulido profesor de la unam (México) y a Abel Rodríguez, ex presidente de Fecode y ex secretario de educación de Bogotá. Estas entrevistas se hicieron en el II encuentro de maestros que hacen Investigación desde la escuela realizado en Santa Marta del 22 al 26 de julio del 2002. es, entonces, una representación formada por un conjunto de ideas coordinadas e imágenes coherentes que permiten a las personas razonar frente a situaciones problema. La concepción evidencia una estructura mental subyacente, responsable de esas manifestaciones contextuales.

En cuanto a la formación del maestro para adquirir conocimientos y habilidades sociales que le permitan desempeñarse con eficiencia en la relación escuela-sociedad, se han caracterizado tres ejes articuladores, según Juan Carlos Tedesco (2000), escuela y familia, eje que ha estado centrado en vínculos de apoyo en procesos formativos; escuela y medios de comunicación, vistos como agentes de socialización y otras veces como instrumentos en el proceso de aprendizaje; y escuela y empresa, vista como una aliada en la formación para el trabajo. La relación escuela-comunidad, en el sentido de cooperación recíproca, no se contempla ni se ha considerado necesaria y pertinente en la formación de los maestros, es decir, no se ha asumido en forma suficientemente rigurosa y constante para hacer de la escuela una institución posibilitadora y dinamizadora del desarrollo comunitario y social; una institución con un papel social más allá del aula, ni tampoco se han valorado las personas ni los recursos de la comunidad como factores importantes para el proceso educativo.

Para comprender la importancia del concepto de experiencia que se trabaja en esta investigación, se toma como referente al pedagogo latinoamericano Paulo Freire (1921-1997), para el cual "el hombre es esencialmente un ser inconcluso, en proceso de compleción” (1974, p. 15). En este proceso, la experiencia es un ejercicio de reincorporación de los hechos y acontecimientos que el sujeto vivencia en el transcurso de su vida en forma consiente y acumulativa a su conciencia, y que a la vez le permiten pensar y actuar de determinada manera frente a los problemas que afronta en su cotidianidad. Freire traslada este concepto a la educación y la denomina educación problematizadora, ésta "propone a los 
hombres su situación como problema -en la cual- los hombres se apropian de ella como situación histórica, y, por lo tanto, capaz de transformarla" (entrevista a Freire, 1974, p. 15).

El concepto de experiencia ubicado en la educación problematizadora de Freire es importante para construir la noción de dimensión sociopolítica del maestro, porque:

[...] como experiencia específicamente humana, la educación es una forma de intervención en el mundo. Intervención que va más allá del conocimiento de los contenidos... implica tanto el esfuerzo de reproducción de la ideología dominante como de su desenmascaramiento. La educación dialéctica y contradictora no podría ser una u otra de esas cosas. La educación nunca fue, es, o puede ser neutra "indiferente" (Freire, 1997, p. 95).

Desde los anteriores presupuestos, la dimensión sociopolítica del maestro requiere de por lo menos cinco componentes: a) una toma de conciencia de las realidades sociales y políticas que afectan la sociedad de manera global y local, b) conocimientos pertinentes para la comprensión de las realidades sociales y políticas;c) comprender la forma como esas realidades globales afectan la comunidad cercana a su campo de trabajo; d) poseer conocimientos y saberes pedagógicos que permitan comprender y comunicar esas realidades de tal manera que potencien en las comunidades un diálogo y la toma de conciencia de su papel transformador, y e) una capacidad de acción frente a las realidades.

Es importante reconocer que durante la última década del siglo XX se llevó a cabo en el país, por parte del Ministerio de Educación, la Asociación Colombiana de Facultades de Educación (Ascofade), Asociación Nacional de Escuelas Normales (Asonen), Federación Colombiana de Educadores (Fecode), y algunos intelectuales y pedagogos, un proceso de reflexión sobre la formación de maestros, el cual generó la promulgación de los Decretos 3012 de 1997, por el cual se adoptan disposiciones para la organización y el funcionamiento de las escuelas Normales superiores y el Decreto 272 de 1998, por el cual se establecen los requisitos de creación y funcionamiento de los programas académicos de pregrado y posgrado en educación ofrecidos por las universidades y por las instituciones universitarias. Estos dos decretos están más dirigidos, por su naturaleza, a la normatización que a la conceptualización, razón por la cual es tarea de los investigadores, maestros y directivos de las instituciones educativas la construcción de los elementos conceptuales que orienten la formación de los maestros.

En el Decreto 3012, el artículo cuarto le da a la dimensión ética, cultural y política de la profesión educativa la categoría de núcleo del saber, lo cual significa que hace parte de los seis ejes sobre los cuales descansa la formación de maestros, de ahí que la conceptualización y comprensión de esta dimensión es hoy una prioridad para la construcción de unas nuevas condiciones sociopolíticas del micro-contexto de la escuela, las cuales serán una semilla para construir una sociedad más justa.

En lo referente al Decreto 272, se encuentran más elementos de la dimensión sociopolítica que en el Decreto 3012. El artículo primero establece que:

Los programas académicos de pregrado y postgrado en educación han de contribuir al fortalecimiento de los procesos de desarrollo educativo, social, económico, político, cultural y ético que requiere el país y a hacer efectivos los principios de la educación y los valores de la democracia participativa definidos por la Constitución política de Colombia, en el contexto de un estado social de derecho.

En este mismo sentido el artículo tres promulga que:

Los programas académicos tienen el compromiso con la sociedad de formar profesionales capaces de promover acciones formativas, individuales y colectivas, y de comprender y actuar ante la problemática educativa en la perspectiva del desarrollo

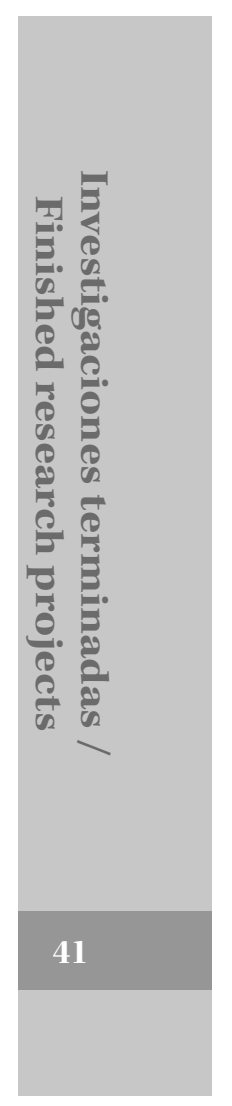

Revista Rastros Rostros - Volumen 13, Número 25 - enero-junio 2011 
integral humano sostenible, mediante el logro y fortalecimiento de capacidades como: literal e) crear ambientes y situaciones pedagógicas que le permitan a él (maestro) y al estudiante, como sujetos de formación, autoconocerse e impulsarse hacia la comprensión y transformación de la realidad (Decreto 3012).

El Decreto 272, al igual que el 3012, incluye en los núcleos del saber pedagógico la dimensión ética, cultural y política de la profesión educativa. Estas circunstancias favorables al desarrollo de la dimensión sociopolítica presentes en la normatividad actual de la formación de maestros han sido fruto de encuentros entre muchas personas que han estado preocupadas por la defensa de la educación pública y la formación de mejores ciudadanos, y no pueden pasar inadvertidas para los directivos y maestros de las instituciones formadoras de maestros.

Dadas las circunstancias que se dan en el país a partir de la Constitución de 1991, cuando se promulga a Colombia como un Estado social de derecho y la circunstancia que en el departamento de Santander hay maestros y maestras que han realizado experiencias exitosas en la re- dimensión del papel social del maestro, es importante develar los saberes y experiencias que han sido importantes en la consolidación de las concepciones, la formación que han recibido y las experiencias de las maestras que integran la Mesa por la Calidad de la Educación de Floridablanca.

La pregunta que orientó la investigación fue: ¿cuáles son los componentes de las concepciones pedagógicas, los enfoques en la formación profesional y las experiencias que han contribuido al desarrollo de la dimensión socio-política de las maestras que integran la Mesa por Calidad de la Educación de Floridablanca? Esta pregunta tiene como objetivo analizar los componentes de las concepciones pedagógicas, los enfoques en la formación y las experiencias que han contribuido al desarrollo de la dimensión sociopolítica de las maestras que integran la Mesa por la Calidad de la Educación de Floridablanca (MCEF), esto con el fin de avanzar en la fundamentación para formar maestros y maestras con criterios políticos, creativos y solidarios (elementos fundantes de la misión de la Universidad Cooperativa de Colombia).

\section{Metodología}

La investigación se desarrolló mediante un enfoque cualitativo con la propuesta metodológica de la teoría fundada, la cual presenta las siguientes características.

Se fundamenta en el interaccionismo simbólico. Esta corriente teórica le da un peso específico a los significados sociales que las personas asignan al mundo que los rodea. Según Blumer:

[...] las personas actúan con respecto a las cosas e inclusive frente a las personas, sobre la base de los significados que unas y otras tienen para ellas; los significados son productos sociales que surgen durante la interacción. Los actores sociales asignan significados a situaciones, a otras personas, a las cosas y a sí mismos a través de un proceso de interpretación” (Blumer, citado en Sandoval Casilimas, 1991, p. 51).

De acuerdo con lo expuesto por Blumer (p. 52), el objeto a investigar no es parte de la cultura en general o de productos culturales en particular, sino de los procesos de interacción a través de los cuales se produce la realidad social, dotada de significado, en este caso, la pertenencia de las maestras integrantes de la Mesa por la Calidad de la Educación.

El desarrollo del proceso investigativo no es lineal, es decir, los datos se categorizan en forma abierta a través de un proceso de construcción sistemática, tomando en cuenta los datos obtenidos de tal manera que éstos pueden generar nuevas interpretaciones hasta llegar a la categoría núcleo, el ordenamiento de informaciones y la escritura de los elementos de análisis para entender la dimensión sociopolítica del maestro. 


\section{Momentos del proceso de investigación}

La investigación tuvo una duración de dos años (2001 y 2002). Durante el primer año se hizo un acercamiento a la situación problemática y se precisó la temática de estudio: la dimensión sociopolítica de los maestros. Durante el segundo año se llegó a la determinación del sujeto de estudio (Mesa por la Calidad de la Educación del municipio de Floridablanca), el acercamiento a los antecedentes investigativos en el campo durante el primer semestre del $2002 \mathrm{y}$ en el segundo semestre el trabajo de campo y el análisis de la información. A continuación aparecen descritos los momentos y las fases de cada uno.

\section{Primer momento}

Acercamiento a la situación problemática desde los intereses, las necesidades y la teoría.

Primera fase: esta fase se realizó durante el 2001 y consistió en identificar la situación problemática en la formación de maestros que fuera relevante intervenir desde dos presupuestos: uno, relacionado con los intereses profesionales en cuanto al trabajo en una Facultad de Educación y otro, personal en cuanto a una inquietud frente a una reflexión sobre la dimensión sociopolítica del maestro.

En esta fase se hizo una exploración sobre las experiencias de maestros que trabajan en interacción con las comunidades en el país, realizando un análisis de las más significativas. Se hizo igualmente una revisión sobre cómo se ha tomado la dimensión sociopolítica en las reformas educativas desde 1821 hasta 1998, cuando se expidieron los Decretos 3012, sobre reestructuración de las Normales y 272, sobre acreditación de los programas de formación de maestros.

Segunda fase de indagación teórica: la característica fundamental de esta fase es la búsqueda de información sobre las temáticas centrales de la investigación: el concepto de concepciones y prácticas, y la dimensión sociopolítica. Para el primer concepto, la estrategia fundamental la constituyó el colectivo de la línea, concepciones y prácticas pedagógicas de la maestría bajo la orientación de su coordinador. En las sesiones se presentaron ponencias sobre temáticas como el concepto de concepciones y prácticas, cómo evolucionan las concepciones y cómo se transforman; se emplearon como instrumentos las ponencias, la complementación a las mismas y la socialización de los avances sobre el tema de concepciones y prácticas, en las sesiones del colectivo de concepciones.

La segunda temática sobre la dimensión sociopolítica fue un proceso de construcción individual elaborado a partir de los trabajos de Paulo Freire y Guillermo Hoyos.

\section{Segundo momento: trabajo de campo}

El trabajo de campo se define como el momento en la cual se trabajó con las integrantes de la Mesa por la Calidad de la Educación, para la implementación de los instrumentos propuestos.

Primera fase: en ésta se diseñaron tres instrumentos: entrevista a profundidad, testimonio y diarios de campo tomados en los grupos de discusión.

Segunda fase: ésta se realizó a través de encuentros individuales para la realización de la entrevista a profundidad que había sido conocida previamente por cada una de las integrantes de la mesa. Para el testimonio se entregó con anterioridad una carpeta que contiene: los objetivos de la investigación, las preguntas problemáticas y una matriz que muestra los objetivos de cada instrumento.

Para los grupos de discusión se realizaron citaciones previas con la finalidad de socializar los avances en el proceso de recolección de la información. Se asistió a las reuniones durante un año; en estas reuniones se dialogó sobre problemas que surgen en el sector educativo, otras fueronpara

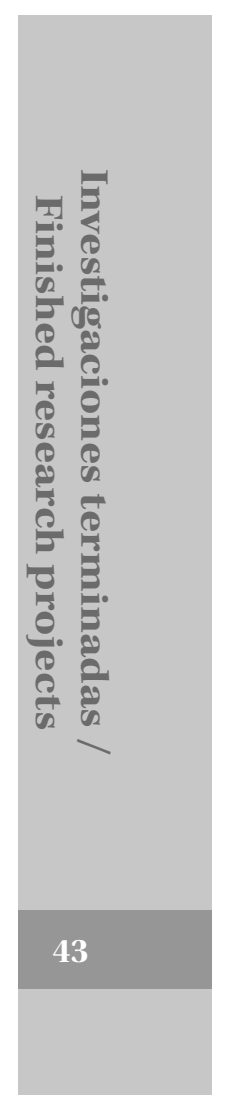

Revista Rastros Rostros - Volumen 13, Número 25 - enero-junio 2011 
dar informes sobre actividades y organizar un foro sobre la calidad de la educación en el municipio. Estos conversatorios se grabaron para apoyar la elaboración de los instrumentos de análisis.

El proceso de investigación es cíclico y continuo, es decir, que, en el momento del análisis de la información, una vez que en el primer nivel de codificación (codificación abierta) empieza a emerger una primera estructura de variables con más fuerza que otras, se hace necesario regresar a la búsqueda de información. Para este trabajo se hicieron entrevistas a profundidad a expertos en el tema, asistentes al Tercer encuentro internacional de maestros que hacen investigación desde la escuela.

\section{Tercer momento: análisis de la información}

Primera fase: codificación sustantiva o abierta. En esta fase se construyeron rejillas para el análisis de la información, éstas permitieron perfilar los componentes en las concepciones de los maestros: lo social, lo político y lo pedagógico, tomadas de las entrevistas a profundidad hechas a cada integrante de la mesa. Para analizar la influencia de los enfoques en la formación recibida por las maestras, se elaboró una rejilla, en la cual se empezó el rastreo de los componentes en lo social y lo político que se perfilaron como componentes de las concepciones, y en las experiencias fueron surgiendo las académicas, las comunitarias y otras de menor importancia.

Segunda fase: codificación selectiva o axial. El diseño de la teoría fundada permite en forma cíclica retornar al trabajo de campo para completar información hasta lograr la saturación, es decir, cuando ya los nuevos datos no agregan elementos relevantes. En esta fase se realizó una entrevista a profundidad a seis maestros que mostraron, por sus experiencias y su producción intelectual, comprensión de algunos elementos que forman la dimensión sociopolítica del maestro.

\section{Hipótesis}

El estudio parte de tres hipótesis: las concepciones pedagógicas de las maestras que forman el colectivo de la Mesa por la Calidad de la Educación del Municipio de Floridablanca demuestran que éstas poseen unos saberes que se han enriquecido por la acción colectiva, desde tres componentes: el primero, desde el ámbito de lo moral con una resignificación de los sentimientos morales y de una sensibilidad moral sustentada desde una acción comunicativa. El segundo, desde una redimensión de lo ético, entendida como el deber ser y el deber hacer del hombre desde lo individual para trabajar por una ética "intersubjetiva", es decir, que han avanzado hacia la comprensión de una ética social, y el tercer componente, una redefinición de lo pedagógico desde dos aspectos: una valoración del contexto cultural de la escuela, con lo cual aparece una ampliación de las fronteras de acción de estas maestras, y una comprensión del carácter político de la educación.

En cuanto a la formación de las maestras que hacen parte del colectivo de estudio, se parte de la hipótesis de que la formación recibida por las maestras que integran la Mesa por la Calidad de la Educación no fue determinante en el desarrollo de la dimensión sociopolítica, una vez que han sido formados con los presupuestos de las reformas de 1963, 1968, 1978 o 1984, que no contemplaban el papel del maestro desde lo social ni lo político.

En lo que hace referencia a las experiencias del colectivo de estudio, se parte de la hipótesis de que las maestras de la Mesa por la Calidad de la Educación de Floridablanca han trabajado en proyectos que les han permitido construir experiencias con una dimensión social en contextos afectados por necesidades socioeconómicas y educativas, lo cual ha generado en ellas un sentido de identidad con el contexto donde han desarrollado sus experiencias en el adelanto de la labor pedagógica. Adicionalmente, el contacto con 
personas o entidades del liderazgo social les ha potenciado una serie de competencias pedagógico-políticas que las compromete con una nueva forma de asumir la educación desde un liderazgo colectivo.

\section{Población y características}

El colectivo está formado por diez maestras oficiales del municipio de Floridablanca cuyas características son:

Tabla 1. Rango de edad del colectivo Mesa por la Calidad de la Educación de Floridablanca

\begin{tabular}{|c|c|}
\hline Rango de edad & Número de maestras \\
\hline $35-40$ & 2 \\
\hline $41-45$ & 1 \\
\hline $46-50$ & 4 \\
\hline $51-55$ & 3 \\
\hline
\end{tabular}

Fuente: la autora

Con respecto al nivel académico, cinco tienen título de Magíster y cinco de especialistas en diferentes áreas relacionadas con la educación.

En cuanto a las funciones que desempeñan en la educación oficial, seis ejercen funciones de dirección y coordinación, y cuatro son docentes de educación básica.

\section{Relación: categorías, instrumentos y proceso de análisis}

\section{Categoría: lo social}

Lo social es para esta investigación un proceso de conceptualización e interiorización de unos conocimientos y valores sociales en constante construcción, lo cual implica entender la sociedad como una producción en la que los hombres y mujeres son actores de cambio, es decir, que la sociedad se transforma pero teniendo como base el conocimiento y la valoración del contexto, desde los cuales se proyecta para poder pensar y actuar globalmente.

Tabla 2. Relación entre los instrumentos y el proceso de análisis de la categoría núcleo: Io social

\section{Instrumentos}

Esta categoría tiene como instrumento principal la entrevista a profundidad. Las ocho preguntas hacen referencia a sus intereses, a develar sus conceptos frente a las problemáticas sociales.

También se tomaron elementos de los grupos de discusión.

Fuente: la autora

\section{Categoría: lo político}

Lo político en esta investigación es asumido como un proceso que tiene como propósito movilizar el conocimiento y las acciones para minimizar los grados de opresión e injusticia en la vida de las comunidades, lo cual está íntimamente ligado a lo pedagógico por cuanto contribuye a crear un imaginario político para generar nuevas condiciones, en las que los principios de igualdad, libertad y justicia se conviertan en principios para estructurar las organizaciones e instituciones. La conceptualización de esta categoría implica resignificar lo moral en el sentido de obrar de acuerdo con normas establecidas para entenderla; de obrar siempre a favor de otros, especialmente quienes están en condiciones de marginación y exclusión; relacionar lo ético con acciones reflexionadas, tanto desde lo individual, como lo colectivo, siempre en la búsqueda de la justicia y la equidad; y valorar la cultura desde una perspectiva crítica (Freire, 1997).

Tabla 3. Relación entre los instrumentos y el proceso de análisis de la categoría núcleo: Io político

\section{Instrumentos}

Discusión en los grupos. Hubo sesiones especiales para analizar el impacto político de las acciones de la Mesa, para lo cual se construyó una rejilla.

Fuente: la autora

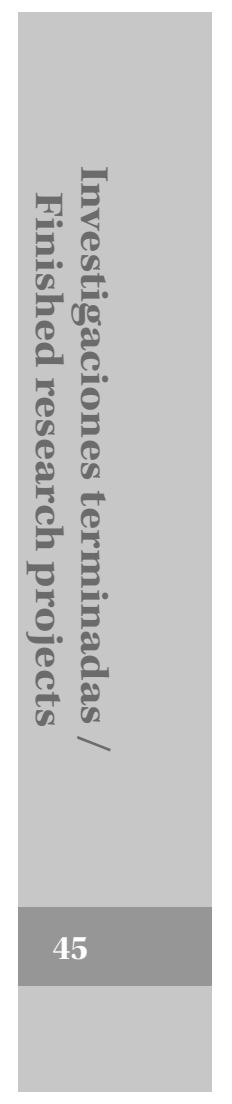

Revista Rastros Rostros - Volumen 13, Número 25 - enero-junio 2011 


\section{Categoría: lo pedagógico}

En esta investigación lo pedagógico se considera como el proceso de crear representaciones simbólicas desde las prácticas pedagógicas, entendidas como un espacio de interacciones comunicativas que tienen como finalidad la promoción del hombre como ser social y político. Esta conceptualización pedagógica implica que las relaciones dadas entre los miembros de la comunidad educativa deben ser dialécticas.

Esta concepción pedagógica se caracteriza por la necesidad de privilegiar la participación activa de todos los miembros de la comunidad educativa y propiciar altos niveles de participación, para ello se requiere el desarrollo de capacidades comunicativas; y la necesidad de reconceptualizar la intencionalidad de los currículos, la investigación y las prácticas de la escuela, con el fin de avanzar en los niveles de participación y comunicación.

Tabla 4. Relación entre los instrumentos y el proceso de análisis de la categoría núcleo: lo pedagógico

\begin{tabular}{|c|c|}
\hline Instrumentos & Proceso de análisis \\
\hline $\begin{array}{l}\text { En la entrevista a profundidad se } \\
\text { hicieron dos preguntas referentes a } \\
\text { este aspecto. Además, todas las pre- } \\
\text { guntas se hicieron con una mirada } \\
\text { sobre lo pedagógico. } \\
\text { Se pidió a cada una de las diez maes- } \\
\text { tras que escribieran un testimonio } \\
\text { sobre su formación y de ahí se toma- } \\
\text { ron conceptualizaciones para hacer } \\
\text { un acercamiento a lo pedagógico. } \\
\text { Entrevista a expertos. }\end{array}$ & $\begin{array}{l}\text { Se tomaron los aportes de las entre- } \\
\text { vistas y se encontró que esta categoría } \\
\text { necesita mayor trabajo a profundidad } \\
\text { para encontrar lo político y social. } \\
\text { Se buscó información en maestros } \\
\text { expertos y se les hizo una entre- } \\
\text { vista, tomando como ejes aspectos } \\
\text { políticos y sociales su relación con la } \\
\text { escuela y la educación. }\end{array}$ \\
\hline
\end{tabular}

Fuente: la autora

\section{Resultados}

\section{Componentes de las concepciones de las maestras integrantes de la Mesa por la Calidad de la Educación en Floridablanca}

El mapa de interrelaciones permite encontrar puntos de encuentro entre las categorías núcleo (lo social, lo político, lo pedagógico) de las concepciones del colectivo de la MCEF para entender la dimensión sociopolítica. En la categoría núcleo de lo social, se pueden establecer los siguientes elementos: a) las concepciones de los maestros identifican a la sociedad como una producción, no como reproducción de patrones culturales. Este componente de lo social les permite ser sujetos activos, creativos, propositivos en los diferentes contextos donde ejercen su profesión; b) los maestros entienden el concepto de transformación como una acción del sujeto en contra de una concepción de adaptación a las circunstancias actuales; c) los maestros reconocen la proyección como interrelación entre el conocimiento de su entorno y el conocimiento de la situación regional y mundial para actuar en la comunidad, y para ello se necesita desarrollar las capacidades para pensar globalmente.

En la categoría núcleo de lo político se encuentran las siguientes elementos: a) relacionan lo moral con el obrar en favor de otros, especialmente quienes están en condiciones de marginación y exclusión, es decir, se sienten comprometidos con estas causas; b) entienden lo ético como acciones reflexionadas tanto desde lo individual como lo colectivo, siempre en la búsqueda de la justicia y la equidad; c) se asume la valoración de la cultura desde una perspectiva crítica (Freire, 1997).

En la categoría de lo pedagógico, aparecen los siguientes elementos: a) las relaciones que se dan entre los miembros de la comunidad educativa deben ser dialécticas; b) en las relaciones con la comunidad educativa se necesita privilegiar la participación activa de todos sus miembros; c) para propiciar altos niveles de participación se deben desarrollar capacidades comunicativas; d) para avanzar en los anteriores propósitos se hace necesario reconceptualizar la intencionalidad de los currículos, la investigación y la prácticas de la escuela. 
Mapa de relaciones de los componentes de las concepciones de las maestras de la Mesa por la Calidad de la Educación

Relacionando las tres categorías núcleo que se encontraron en la noción de dimensión sociopolítica (lo social, lo político y lo pedagógico), se establece el siguiente mapa de relaciones:

\section{Lo social como potenciador de lo pedagógico y lo político: una concepción sociopolítica fundamentada en nuevas reconceptualizaciones éticas y morales}

Las concepciones de estas maestras tienen puntos de encuentro, especialmente por el carácter social que le imprimen a la educación. Para ellas, la educación tiene como función primordial garantizar el derecho a una educación de calidad contextualizada de acuerdo con las necesidades de las personas y las comunidades.

\section{La eficiencia en el cumplimiento de funciones administrativas: una concepción reduccionista de lo sociopolitico}

Es una relación que se da en dos integrantes del colectivo, dado que sus funciones directivas les han estructurado un pensamiento de corte funcionalista. Sin embargo, el hecho de pertenecer a un colectivo dialógico ha hecho que avancen en la comprensión de lo administrativo desde las necesidades sociales, más que desde la norma.

\section{La primacía de lo pedagógico: una concepción que necesita enriquecerse}

Lo pedagógico se toma desde una visión reduccionista, en su comprensión tradicional de cumplimiento de normas emanadas del Ministerio de educación y las secretarías de educación y en el aula sólo aparece asociado a las didácticas. En una concepción más avanzada de corte freiriano lo pedagógico es político (1997).

\section{La prioridad de la defensa del medio ambiente: una concepción que enfatiza lo contextual}

Las maestras que se agrupan en esta categoría lideran en el municipio proyectos ambientales y su formación básica son las ciencias naturales. Se destaca que poseen una visión macro de los problemas ambientales y tienen un gran compromiso con la conservación y protección del medio ambiente; precisamente ese interés las ha traído a la Mesa y ha hecho posible su permanencia.

\section{La formación de las maestras del colectivo: entre el afán transmisionista de conocimientos, la formación en valores religiosos y la disciplina entendida como orden}

La mirada crítica y el análisis que se hizo a la formación de maestros se basó en dos fundamentos básicos: el primero parte de un análisis que prioriza la visión crítica en las relaciones sociales, políticas y pedagógicas; en segundo lugar, se toman los puntos de vista de las diez maestras sobre su formación, a través del testimonio y los planteamientos expresados por los investigadores en la entrevista a expertos.

La investigación mostró que la formación profesional recibida por las maestras del colectivo, da razón de cuatro enfoques que actúan como limitantes para el desarrollo de la dimensión sociopolítica.

- Un enfoque asignaturista y fragmentario, que toma como objeto de estudio realidades fuera de su contexto, aspecto que dificultó la comprensión y redujo el aprendizaje a la simple memorización. Además les quitó a estas maestras la posibilidad de comprender las problemáticas de su país, de su departamento y de su municipio.

- Un enfoque reproduccionista de los valores de la sociedad. Esta concepción se forma desde una visión heterónoma, para la sumisión, para ser un reproductor del sistema; este enfoque

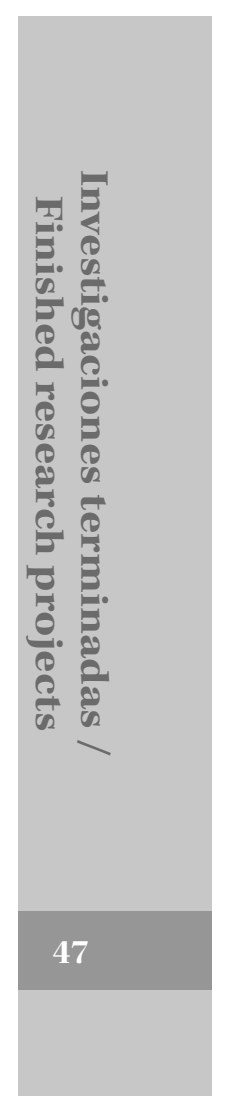

Revista Rastros Rostros - Volumen 13, Número 25 - enero-junio 2011 
imposibilita la transformación porque no se desarrollan capacidades para la proyección, para la autonomía.

Se formó para rendir culto al conocimiento, es decir, el papel del estudiante es repetir un conocimiento que ya está científicamente comprobado, lo que generó una actitud pasiva y una neutralidad valorativa del conocimiento. Este enfoque dificulta el desarrollo de la dimensión sociopolítica porque contribuye a la concepción reproduccionista de la sociedad, desde la cual la realidad social es una consecuencia lógica de los procesos sociales y no una consecuencia de las desigualdades que pueden transformarse.

- Un enfoque centrado en la racionalidad de un pensamiento único, disgregado a través de asignaturas que mostraban el conocimiento fraccionado en partes. Este conocimiento fue impartido por maestros especialistas que no mostraron una cosmovisión integradora. Este enfoque limita la formación de la dimensión sociopolítica porque no permite comprender la realidad social a la luz de diferentes teorías, sino que fracciona la realidad.

- Un enfoque que enfatiza en la formación de corte competitivo e individualista. Este problema fue quizás el más determinante para crear una sociedad ajena a la comprensión de lo social y lo político. En la formación de los maestros este problema es más grave porque el maestro reproduce los valores en los que ha sido formado. Las maestras del colectivo tienen aún en su inconsciente que fueron formadas en valores que les han permitido desempeñarse con éxito en su profesión.

Para el análisis y la conceptualización sobre la visión crítica de las relaciones sociales y pedagógicas se utiliza el término foucaultiano de "inversión", tomado como un espacio que invierte las relaciones de saber y de poder (Foucault, 1977). El sentido de la inversión da la idea, en la primera afirmación, acerca de cómo fueron formadas las maestras del grupo de estudio, y en la segunda parte, del deber ser de la formación para desarrollar en los maestros la dimensión sociopolítica. Según la información recogida se encontraron cinco inversiones:

Primera inversión: de problemas sociales descontextualizados a problemas del contexto.

Segunda inversión: del problema de una concepción reproduccionista de sociedad a una concepción evolucionista y transformadora.

Tercera inversión: de problemas sobre la neutralidad valorativa del conocimiento a problemas sobre construcción de conocimientos para flexibilizar y entender las transformaciones socioculturales.

Cuarta inversión: del problema de la racionalidad del pensamiento único a la construcción de nociones de integración de saberes, de experiencias de trabajo comunitario en espacios de cohesión social.

Quinta inversión: de una formación de corte competitiva e individualista a la formación de sujetos actores de cambio.

\section{La experiencia de las maestras en contextos sociales caracterizados por la marginación y exclusión: factor determinante para el desarrollo de la dimensión sociopolítica}

La experiencia de las maestras de la Mesa por la Calidad de la Educación se ha desarrollado especialmente en cinco contextos que guardan entre sí algunas similitudes: tres han tenido la experiencia de trabajar en colegios cooperativos; tres han trabajado en colegios privados, hay una que incluso aún está ubicada en un colegio privado que tiene convenio con el municipio, brindando a cambio del nombramiento de maestros oficiales una jornada complementaria para niñas de escasos recursos económicos; tres han trabajado en el sector rural; dos maestras han trabajado con adultos en programas especiales; tres de estas maestras tienen experiencia como profesoras universitarias. 
De las diez maestras del colectivo, hay algunas que han desempeñado su profesión en dos contextos de los anteriormente relacionados, por ejemplo, la docencia universitaria la han ejercido en forma simultánea a la docencia en primaria.

En cuanto a los niveles en los cuales han ejercido la docencia, prevalecen las experiencias en la educación primaria, seguida de la educación básica secundaria. En lo que realmente hay grandes similitudes en las experiencias es en las características de los contextos donde estas diez docentes han ejercido su labor: en un $90 \%$ se desempeñan o han trabajado en sectores de los estratos uno y dos, en los cuales tienen que vivir las personas de menos recursos económicos que no pueden satisfacer las necesidades básicas de sus hijos e hijas, razón por la cual los maestros y maestras que se desempeñan en estos sectores se encuentran diariamente en la escuela con una cantidad de factores adversos para el buen aprendizaje de los estudiantes y para construir valores para una sociedad que los excluye y margina; con este reto se encuentran diariamente cientos de maestros en el departamento y el país.

En la actualidad, estas diez maestras ejercen distintas funciones: tres se desempeñan como docentes, dos en los niveles de educación básica secundaria y una en la sección nocturna, de instituciones ubicadas en los estratos uno, dos y cuatro; dos son coordinadoras académicas de colegios oficiales ubicados en estratos uno y dos; una es directora de núcleo del municipio; una coordinadora de un programa en el municipio; una integrante es coordinadora de un proyecto a nivel departamental; una orientadora de un colegio oficial ubicado en estrato dos; y una directora de una institución ubicada en el estrato cero.

Las experiencias del colectivo que fue estudiado presentan cuatro características:

- Las experiencias en y con la comunidad son un factor irremplazable en el desarrollo de la dimensión sociopolítica de las maestras del colectivo.
- Las relaciones escuela-comunidad se consolidan a través de la elaboración de proyectos.

- Las relaciones escuela-comunidad requieren del reconocimiento de los elementos culturales de la comunidad.

- Las relaciones escuela comunidad necesitan de la consolidación de relaciones horizontales y de la construcción de condiciones de igualdad.

\section{Conclusiones}

Los componentes de las concepciones de las maestras del colectivo de este estudio muestran algunos factores caracterizados por el apego a la religiosidad, la rigurosidad y el orden, que ellas consideran importantes, junto con una creencia, en menor frecuencia, sobre la importancia de la cientificidad del conocimiento. Sin embargo, en las concepciones de la mayoría de estas maestras se encuentran componentes de lo sociopolítico, que a grandes rasgos muestran las siguientes tendencias:

- Aparecen en forma clara, tanto conceptualmente como en sus prácticas, tres fenómenos sociales: producción, transformación y proyección. En cuanto a la producción, ellas han avanzado hacia entender que debe trascenderse el discurso y pasar a la acción. En este sentido ellas producen documentos, propuestas de acción, orientan los foros que se hacen en el municipio y comunican a través de cartas los factores que de una forma $u$ otra son importantes para la educación del municipio. En lo pedagógico, muestran una tendencia hacia lo que llaman procesos productivos tomados en su dinámica constante de reconocimiento del otro, y conciben la sociedad como producción histórica. En el concepto de transformación, a través de las diferentes intervenciones, muestran la necesidad de transformar la educación; estas afirmaciones las sustentan desde el conocimiento del contexto, que es una constante

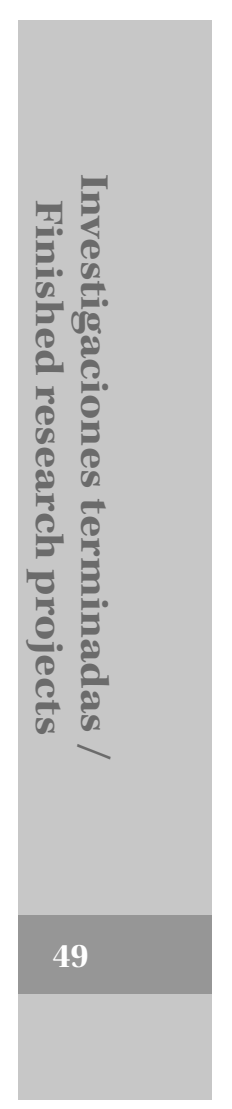

Revista Rastros Rostros - Volumen 13, Número 25 - enero-junio 2011 
en las diez maestras, y es un motivo frecuente de reflexión. La proyección se muestra como una actitud que impulsa a las personas hacia el trabajo a favor de los demás en doble sentido; de un lado, dar de lo que se tiene, en este caso saber y poder como servidoras públicas, y de otro, planear el futuro como una forma de pensar que va más allá de la acción inmediata. La consecuencia relevante de estas conceptualizaciones es la comprensión de que se necesita formar a los niños, los jóvenes, los adultos y los maestros como actores sociales de cambio, porque es urgente desarrollar capacidades para la proyección que permitan al sujeto comprometerse con el mejoramiento de la calidad de vida propia y de los otros, en forma autónoma.

- La comprensión del papel social de la educación, de la escuela y del maestro como gestor de planes, programas y proyectos. Para cumplir este compromiso las maestras que han participado en proyectos, han desarrollado, según ellas, acciones en su contexto que buscan concientizar a los ciudadanos de Floridablanca sobre la exigencia de la garantía del derecho a la educación y han gestado movilizaciones a favor de la educación. Este proceso generado por las maestras ha significado para ellas igualmente una movilización a nivel personal, intelectual y afectivo.

- Una reconceptualización de lo moral que trasciende el deber con la sociedad, con las normas, para la búsqueda del bien común y que se enmarca en los sentimientos y en la sensibilidad moral, es decir, rompe las fronteras de lo privado y se proyecta hacia lo colectivo como un derecho que exige de cada ciudadano una respuesta.

- Una resignificación de la ética que se manifiesta en la constante búsqueda de coherencia entre el pensar y el actuar de la mesa como grupo, es decir, se avanza hacia la comprensión de una ética intersubjetiva.
- Una ampliación del concepto tradicional depedagogía asociado a la didáctica, para comprender lo pedagógico como una polifonía, como un campo de saberes múltiples que buscan el encuentro con el otro, para potenciarle todas sus capacidades, en función de los otros que le dan razón a su existencia. La pedagogía desborda los límites incluso del trabajo en el aula, para comprender el papel de la escuela más allá de lo inmediato.

- La comprensión del papel político de la educación, manifestado en el convencimiento que cada integrante tiene sobre la necesidad de trabajar por la calidad de vida, a través de la educación, para lo cual el maestro debe trascender la participación delegataria, por la búsqueda de una participación real con sentido. Las maestras de este colectivo forman parte de diferentes instancias de participación en las cuales se toman decisiones importantes sobre la educación.

Esta investigación muestra algunos elementos para avanzar hacia nuevas dimensiones en la formación de maestros, quienes serán los profesionales encargados de la formación de nuevos ciudadanos para un Estado Social de Derecho.

\section{Referencias}

Blumer (1996), “Investigación cualitativa”, en Sandoval Casilimas, C. A., Módulo Cuatro, Bogotá, Icfes.

Freire, P. (1997), Pedagogía de la autonomía, México, Siglo XXI.

Foucault, M. (1977), Vigilar y castigar, México, Siglo XXI.

De Vecchi, G. A. (1995), Los orígenes del saber, Sevilla, Diada.

Samaniego, A. (1974), "Entrevista a Paulo Freire”, en Cuadernos de educación, núm. 11, Cooperativa laboratorio educativo, Caracas.

Tedesco, J. C. (2000), "Los desafíos de las reformas educativas en América Latina”, en Pedagogía y saberes, núm. 14, Bogotá. 